\title{
A Quantum Chemical Study on Some Schiff Bases as Inhibitors of Mild Steel Corrosion in HCl Solution
}

\author{
Shuangkou Chen", Yuting Ren, Bei Luo, Yinying Guo, Ying Peng \\ College of Chemistry and Chem-engineering, Chongqing University of Science and Technology, \\ Chongqing 401331, China \\ *E-mail: cskcn@yeah.net
}

doi: $10.20964 / 2019.04 .34$

Received: 18 May 2018 / Accepted: 2 July 2018 / Published: 10 March 2019

\begin{abstract}
A quantum chemical study using a DFT/6-31+G(d) method has been performed on three types of Schiff base compound that are used as corrosion inhibitors for mild steel to determine the relationship between their molecular structures and their inhibition efficiency $(I E)$. HOMO orbital $\left(E_{\mathrm{HOMO}}\right)$ and LUMO orbital ( $E_{\text {LUMO }}$ ) energies and other physical properties have been calculated, with these results showing that $I E$ had a good linear relationship to $\Delta E, \eta, \sigma$ and $Q_{N}$ charge (imino nitrogen). These theoretical results were in accord with previously reported experimental results and have been used to identify some new homologous Schiff base compounds that are predicted to exhibit better corrosion inhibition performance.
\end{abstract}

Keywords: modeling studies; corrosion inhibition; Schiff base; prediction of inhibition performance

\section{$\underline{\text { FULL TEXT }}$}

(C) 2019 The Authors. Published by ESG (www.electrochemsci.org). This article is an open access article distributed under the terms and conditions of the Creative Commons Attribution license (http://creativecommons.org/licenses/by/4.0/). 